\title{
VACUUM SYSTEM FOR THE LNLS 500-MeV BOOSTER SYNCHROTRON
}

\author{
R.O. Ferraz, M.J. Ferreira, F.R. Francisco, and M.B. Silva, LNLS, Campinas, Brazil
}

\section{Abstract}

We present a summary of the commissioning and performance of the vacuum system of a $500-\mathrm{MeV}$ booster synchrotron recently built at LNLS as part of a new injector for the LNLS light source. The main vacuum parameters of the synchrotron are pressure below $5 \times 10^{-7} \mathrm{~Pa}$ (lifetime of $1-2$ hours), no in-situ baking, no cooling system, and a short recovery time after ventilation. All parts of the system are made of $1 \mathrm{~mm}$ thick AISI 316L stainless steel. The chambers were pre-baked before installation.

\section{INTRODUCTION}

The Brazilian National Synchrotron Light Laboratory, LNLS, operates a synchrotron light source consisting of a $1.37 \mathrm{GeV}$ electron storage ring and a $120 \mathrm{MeV}$ injector. Here we present a summary of the design, commissioning and performance of the vacuum system of a $500-\mathrm{MeV}$ booster synchrotron[1]. All the system was designed with the following requirements:

- Operation pressure $5 \times 10^{-7} \mathrm{~Pa} \mathrm{~N}_{2}$ equivalent at $500 \mathrm{MeV}, 70 \mathrm{~mA}$ and life-time 1-2 hours.

- Residual gas free of hydrocarbons.

- The system must allow new development.

- The accelerator must also operate in storage mode.

Commissioning of the transport line from injector to the booster started in January 2000 and commissioning of the booster started November 2001. Full energy operation was first achieved in December. At present, $40 \mathrm{~mA}$ of beam dynamic pressure in the system is $4 \times 10^{-7} \mathrm{~Pa}$, the transport line is in the $10^{-6} \mathrm{~Pa}$ range and $\mathrm{RF}$ cavity shows the pressure $6 \times 10^{-7} \mathrm{~Pa}[2]$. All parts of the system were opened at least once, during installation, after the pre-baking, which allowed us to check the short recovery time. Today, if any one of the cells of the booster needs ventilation to atmospheric pressure, 6 hours later it is possible to inject. The transport line can be operated after 4 hours of pump down under the same conditions.

\section{TRANSPORT LINE FROM INJECTOR}

The transport line from the injector to the booster is a tube of $8 \mathrm{~m}$ longer (fig.1), with $35.1 \mathrm{~mm}$ of diameter. The dipole chambers were laser cut. A dipole to deflect the beam to the booster was installed in February 2000. At the same time, modifications in the diagnostic system were made to help this injection. The diagnostics were beam position monitors, current monitors and screen monitors. The final pressure, without baking, is $10^{-6} \mathrm{~Pa}$ range from the diode $20 \mathrm{l} / \mathrm{s}$ ion pump (IP) current.

\section{BOOSTER}

The booster has $34 \mathrm{~m}$ of circumference with the major axis with $12.3 \mathrm{~m}$ and the minor axis with $7.9 \mathrm{~m}$ (fig.2). There is a straight section with $2 \mathrm{~m}$ for insertion devices. The chambers were designed for easy light extraction, modularity and the mentioned vacuum guidelines. The low thermal load from the beam allowed using stainless steel without a cooling system in the dipole vacuum chambers. The vacuum and magnetic components current in the booster has been achieved. The average space was carefully detailed to include kickers, septa (injection, thin extraction and thick extraction) [3], beam

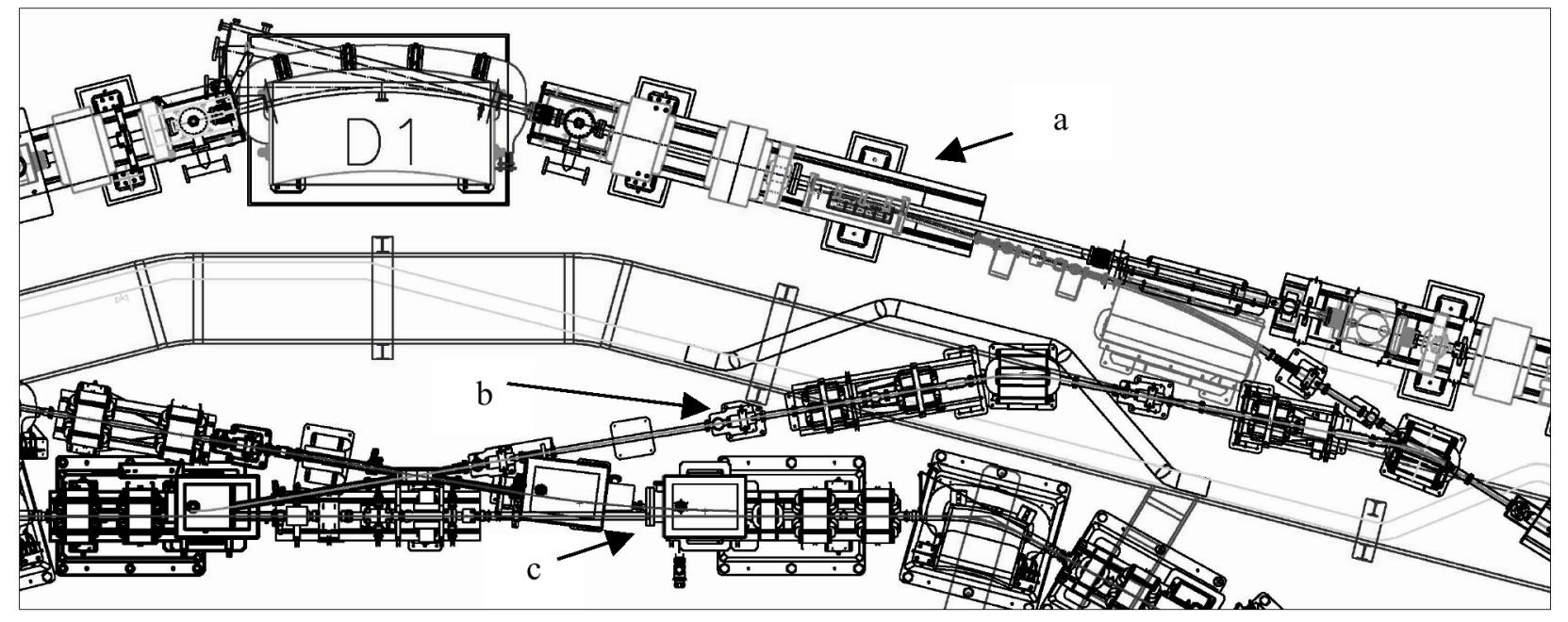

Fig. 1 View of the storage ring (a), transport line from the injector (b), the booster (c). 


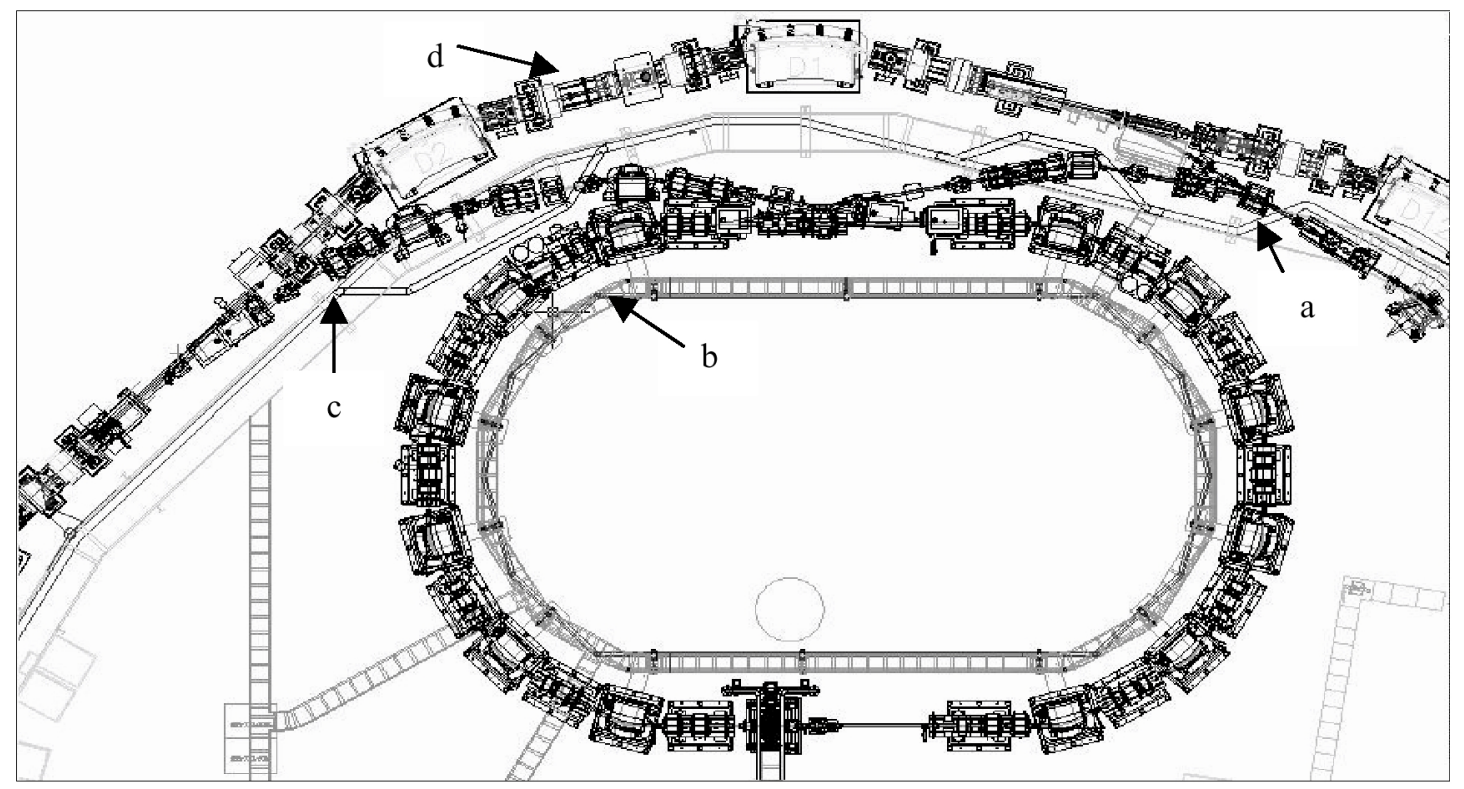

Fig. 2 View of the transport line from injector (a), booster (b), transport line from booster (c) and storage ring (d).

position monitors, button cleaning electrodes, pick ups, radio-frequency (RF) cavity and dipole vacuum chambers, with the sextupoles, quadrupoles, correctors and bending magnets [4]. These constrain let us to choose a CFX NW 50 flange (EVAC) instead of a Conflat ${ }^{\circledR}$ DN 63 standard flange to get the necessary flexibility. The bellows in each side of the dipole vacuum chambers was installed with no shields. The system is pumped by conventional diode $50 \mathrm{l} / \mathrm{s}$ IP in the 12 dipole chambers and 300 l/s in the 3 kickers, 3 septa and one RF cavity. Cold cathode gauges installed in the kickers, septa, RF cavity and one dipole vacuum chamber measure the pressure. The booster has 10 vacuum sector using stainless steel minigate valves specially built with CFX NW 50 flanges and the pump down by the low cost DN 40 all-metal angle valve. Chambers were baked for 5 days at $200^{\circ} \mathrm{C}$, with a turbo-molecular pump. The dipole vacuum chambers were baked with the ion pumps installed. The kickers and septa for injection into the booster and the septa for extraction were baked without IP. In the initial commissioning the mean static pressure was $1.8 \times 10^{-7} \mathrm{~Pa}$ and pressure during operation was $6 \times 10^{-7} \mathrm{~Pa}$. Until now, can be injected a current of $40 \mathrm{~mA}$ in $120 \mathrm{MeV}$ and ramped to $15 \mathrm{~mA}$ in $500 \mathrm{MeV}$ with cycles of $5.8 \mathrm{sec}$.

\section{TRANSPORT LINE FROM BOOSTER}

The transport line from the booster to the storage ring has $13.6 \mathrm{~m}$ (fig. 2) and it is a tube with $35.1 \mathrm{~mm}$ of diameter. We have thick and thin septa for injection into storage ring, which also includes beam position, current and screens monitors. The dipole chambers were laser cut. The final dynamic pressure is $10^{-6} \mathrm{~Pa}$ range by the current of the 201/s IP, without any baking in the chambers.

\section{STORAGE RING}

The storage ring received some modification for the new injection from the booster. The new injection was installed in a straight section including one new kicker, a DCCT beam current monitor and a thin septum. The DCCT current monitor was moved from the original section for a new kicker to take its place. After installation no baking in situ was done in the chambers. Until now, the performance is $540 \mathrm{~mA}$ at $500 \mathrm{MeV}$, and $305 \mathrm{~mA}$ at $1.37 \mathrm{GeV}$ with life-time of $6.2 \mathrm{~h}$ after $30 \mathrm{Ah}$ of accumulated charge.

\section{CONCLUSION}

After installation and initial commissioning, the expected performance of all vacuum booster system was achieved. The mean dynamic pressure of the booster has reached $6.0 \times 10^{-7} \mathrm{~Pa}$ at $15 \mathrm{~mA}$ in $500 \mathrm{MeV}$. The limitation of the lifetime is due to the elastic scattering on the residual gas.

\section{REFERENCES}

[1] P. Tavares et al., Commissioning of the LNLS $500 \mathrm{MeV}$ Booster Synchrotron Light Source. These Proceedings.

[2] R. H. A. Farias et al, RF System for the $L N L S$ Injector Synchrotron. These Proceedings.

[3] A. C. Lira et at, Septum and Kicker Pulsers for the LNLS 500-MeV Booster Synchrotron. These Proceedings.

[4] Liu Lin, et al, "The LNLS 500MeV booster synchrotron. These Proceedings. 